\title{
Using high-abundance proteins as guides for identifying human gut microbiome proteins
}

Stamboulian Moses

Li Sujun

Yuzhen Ye

\section{Video Byte}

Keywords: high-abundance protein, HAP, sample profiling expanded target database, spectra search, human gut metaproteomics, gut, metaproteomics, proteomics, protein, peptide, Microbiome

Posted Date: October 14th, 2021

DOI: https://doi.org/10.21203/rs.3.rs-968294/v1

License: (c) (i) This work is licensed under a Creative Commons Attribution 4.0 International License.

Read Full License 


\section{Abstract}

Human gut microbes have a major impact on health and disease. Understanding gut microbial communities helps to provide insight into treatments for diseases ranging from cancer to inflammatory bowel disease. Recent efforts have significantly expanded the collection of human-associated bacterial genomes. While these new genomes might be used as a universal reference for new metaproteomic studies, a large increase in available data can also make matching more difficult. Now, researchers present a new approach to optimize the use of reference genomes and metagenome assembled genomes (MAGs). The first step uses only high-abundance proteins (HAPs) for a metaproteomic MS/MS database search to derive the composition of the underlying microbial community. Next, the search database is expanded to include all proteins from identified abundant species. Researchers tested the approach, called HAPs guided metaproteomics IDentification (HAPiID), using data from a previous study. The results showed that the two-step method performed significantly faster and was able to identify more peptides than the state-of-the-art reference database search method. This approach represents a novel effective method for constructing target databases for metaproteomic data analysis. 